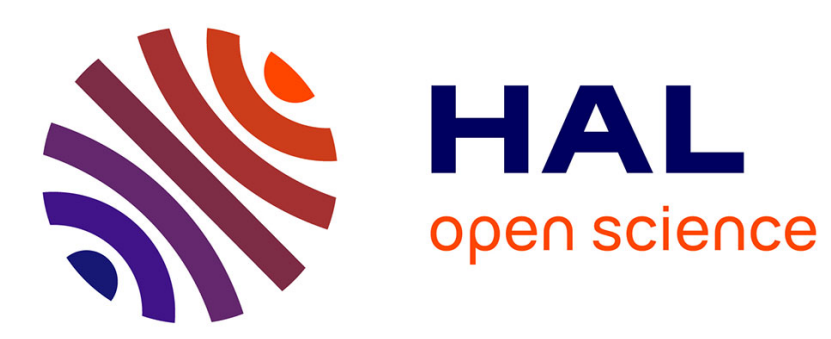

\title{
On the Reconfiguration of Cable-Driven Parallel Robots with Multiple Mobile Cranes
}

Hor Tan, Latifah Nurahmi, Bambang Pramujati, Stéphane Caro

\section{To cite this version:}

Hor Tan, Latifah Nurahmi, Bambang Pramujati, Stéphane Caro. On the Reconfiguration of CableDriven Parallel Robots with Multiple Mobile Cranes. The 5th International Conference on Robotics and Automation Engineering, Nov 2020, Singapore, Singapore. hal-03027651v3

\section{HAL Id: hal-03027651 \\ https://hal.science/hal-03027651v3}

Submitted on 27 Nov 2020

HAL is a multi-disciplinary open access archive for the deposit and dissemination of scientific research documents, whether they are published or not. The documents may come from teaching and research institutions in France or abroad, or from public or private research centers.
L'archive ouverte pluridisciplinaire HAL, est destinée au dépôt et à la diffusion de documents scientifiques de niveau recherche, publiés ou non, émanant des établissements d'enseignement et de recherche français ou étrangers, des laboratoires publics ou privés. 


\section{On the Reconfiguration of Cable-Driven Parallel Robots with Multiple Mobile Cranes}

\author{
Hor Tan, Latifah Nurahmi, Bambang Pramujati \\ Department of Mechanical Engineering \\ Institut Teknologi Sepuluh Nopember \\ Sukolilo Surabaya 60111, Indonesia \\ e-mail: tanhor.19021@mhs.its.ac.id, \\ latifah.nurahmi@me.its.ac.id, pramujati@me.its.ac.id
}

\author{
Stéphane Caro \\ CNRS, Laboratoire des Sciences du Numérique de \\ Nantes, UMR CNRS 6004 \\ 1 Rue de la Noë 44321, Nantes, France \\ e-mail: Stephane.Caro@1s2n.fr
}

\begin{abstract}
This paper proposes a Cable-Driven Parallel Robot (CDPR) with three mobile cranes for search-and-rescue operations. Each mobile crane is composed of a reconfigurable telescopic boom, which can rotate. A cable is mounted from the tip of the telescopic boom to the end-effector. The locations of mobile cranes are fixed, but the configuration of the telescopic boom can be adjusted to enlarge the workspace and to maintain the overall system in equilibrium. The static equilibrium of end-effector and mobile cranes is initially studied to determine the cable tension distribution and wrench-feasible-workspace. To guarantee all mobile cranes to be always in a static equilibrium when executing a given task, the telescopic booms are reconfigured. Three case studies for the reconfigurable CDPR with multiple mobile cranes are presented to compare the tension distribution and workspace size.
\end{abstract}

Keywords - Cable-driven parallel robot, tension distribution, static equilibrium, zero-moment-point, reconfigurable, mobile cranes.

\section{INTRODUCTION}

Cable-Driven Parallel Robot (CDPR) has been developed for both academic and industrial purposes [1]. Various applications of CDPR have been employed in the industrial field, or and some prototypes have been fabricated such as IPAnema [2]. Another type of suspended CDPR was developed in [3,4] for a rapid-life scan. A set of cable arrangements was analyzed and pulleys orientation was reconfigured to adjust the tension value and to increase the manipulator workspace. The prototype has been developed with a cube base frame $0.8 m \times 0.8 m \times 0.8 m$ [5].

A mobile CDPR was developed in the framework of the ECHORD++ FASTKIT project for the industrial requirement with fast pick-and-place operations [6,7]. A planar Mobile-CDPR (M-CDPR) was proposed in [8] by using two mobile bases and each mobile base has two cables. The mobile base must be stable during the moving platform movement; hence Zero Moment Point (ZMP) was applied to analyze mobile base stability [9].

Inverse Kinematics, static equilibrium, dynamics, stiffness, and the workspace of CDPR were investigated in [10]. The methodology to trace the Wrench-Feasible-
Workspace (WFW) based on Available-Wrench-Set (AWS) was proposed [11,12]. In [13], the distribution of cable tensions was shown along with a number of trajectories of the end-effector, for example, horizontal or spherical trajectories.

This paper aims to develop a CDPR with three mobile cranes for search-and-rescue operations. Distribution of cable tensions and mobile cranes stability during reconfiguration are the main focus of this paper. The workspace of the end-effector is considered as wrench feasible workspace (WFW).

\section{ROBOT ARCHITECTURE}

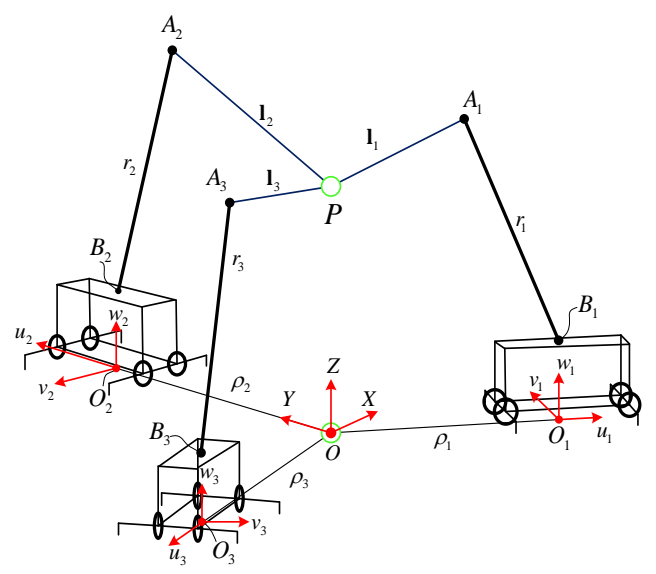

(a) Isometric view

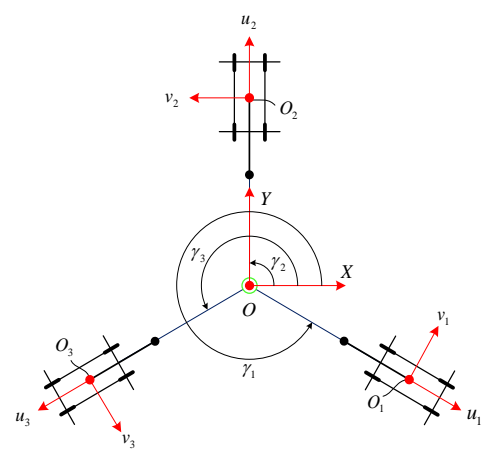

(b) Top View

Figure 1. Schematic of CDPR with mobile cranes 
The robot consists of three mobile cranes with mobile coordinate $\left(u_{j}, v_{j}, w_{j}\right)$ attached at the origin $O_{j}$ and its top view is shown in Fig. 1(a)-(b), respectively. Each mobile crane is located at the origin of the local coordinate $O_{j}$ with distance $\rho_{j}$ from the origin of the fixed frame and the angle $\gamma_{j}$ that is measured counterclockwise from the $\mathrm{X}$-axis as demonstrated in Fig. 1(b). The fixed coordinate frame $\mathcal{F}$ of origin $O$ and axes $(X, Y, Z)$ is located at the ground center. $r_{j}$ and $\beta_{j}$ are the telescopic boom length and tilt angle of the mobile cranes $(j=1,2,3)$, respectively. At point $B_{j}$, the telescopic boom can rotate with an angle $\alpha_{j}$ about the axis $w_{j}$. The end-effector is considered to be a point mass $P$, of cartesian coordinate vector $\mathbf{p}=\left[\begin{array}{lll}x & y & z\end{array}\right]^{T}$. The exit point $A_{j}$ is located at the tip of the telescopic boom and linked to point $P$ by one cable. The vector $\mathbf{a}_{j}^{b}$ of $A_{j}$ is with respect to fixed coordinate.

Point $B_{j}$ is located at the base of the telescopic boom and it is a point connecting the mobile crane $j$ to the telescopic boom. $b_{j}^{z}$ is the height of the mobile cranes. The cable length vector points from point $P$ to point $A_{j}$, as: $\mathbf{l}_{j}^{b}=\mathbf{a}_{j}^{b}-\mathbf{p}$. Accordingly, the unit vector of each cable $\mathbf{u}_{j}^{b}$ is computed as follows:

$$
\mathbf{u}_{j}^{b}=\frac{\mathbf{l}_{j}^{b}}{\left\|\mathbf{l}_{j}^{b}\right\|}
$$

\section{StATIC ANALYSIS}

\section{A. Static Analysis of End-effector}

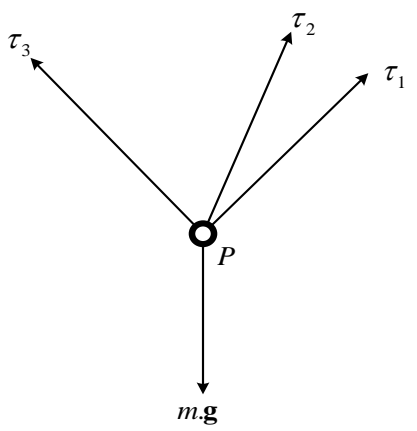

Figure 2. Free-body diagram of an end-effector

In this section, the cables are assumed to be non-elastic and massless. According to the free-body diagram of endeffector at point $P$ shown in Fig. 2, the equation of static equilibrium at point $P$ is expressed as:

$$
\mathbf{W} \tau+\mathbf{w}_{e}=0
$$

where $\tau=\left[\begin{array}{lll}\tau_{1} & \tau_{2} & \tau_{3}\end{array}\right]^{T}$ is the cable tensions vector, and $\mathbf{w}_{e}=[0,0,-m g]^{T}$ is the gravitational force acting at point mass $P$. The gravity vector is denoted as $\mathbf{g}=[0,0,-g]^{T}$ and Wrench matrix is defined as following:

$$
\mathbf{W}=\left[\begin{array}{lll}
\mathbf{u}_{1}^{b} & \mathbf{u}_{2}^{b} & \mathbf{u}_{3}^{b}
\end{array}\right]
$$

Since, $\mathbf{W}$ is square matrix, the cable tensions can be computed as follows: $\tau=-\mathbf{W}^{-1} \mathbf{w}_{e}$, as long as matrix $\mathbf{W}$ is not singular. Then, the cable force $\mathbf{f}_{j}$ can be expressed as: $\mathbf{f}_{j}=-\mathbf{u}_{j}^{b} \tau_{j}$. Each cable tension is maintained to be positive and greater than $1 N$ all the time.

\section{B. Static Analysis of the Mobile Cranes}

Three mobile cranes are fixed on the ground and they altogether should satisfy the condition of static equilibrium. The free-body diagram of the $j$-th mobile crane is illustrated in Fig. 3. Each mobile crane has four jack floats to lift the mobile cranes when the end-effector is performing some tasks. The jack floats have a contact point with the ground at points $C_{1 j}, C_{2 j}, C_{3 j}, C_{4 j}$. The reaction forces at these contact points $\mathbf{f}_{r 1 j}, \mathbf{f}_{r 2 j}, \mathbf{f}_{r 3 j}, \mathbf{f}_{r 4 j}$ are the main role in the static analysis of the mobile cranes. As a consequence, the static equilibrium of the mobile cranes can be mathematically derived for two conditions, namely tipping and rolling. The mobile crane is said to be tipping if it turns over about the $v_{j}$. It occurs because the frontal reaction forces $\left(\mathbf{f}_{r 1 j}\right.$ and $\left.\mathbf{f}_{r 4 j}\right)$ are very high and the rear reaction forces $\left(\mathbf{f}_{r 2 j}\right.$ and $\left.\mathbf{f}_{r 3 j}\right)$ are null. The frontal and rear reaction forces can be written respectively, as follows:

$$
\begin{aligned}
& \mathbf{f}_{f r j}=\mathbf{f}_{r 1 j}+\mathbf{f}_{r 4 j} \\
& \mathbf{f}_{r r j}=\mathbf{f}_{r 2 j}+\mathbf{f}_{r 3 j}
\end{aligned}
$$

By using Newton's first law of motion, the forces equilibrium and moment at point $O$ are defined as follows:

$$
\begin{gathered}
\sum \mathbf{f}=0 \\
\mathbf{f}_{f r j}+\mathbf{f}_{r r j}+m_{I} \cdot \mathbf{g}+m_{I I} \cdot \mathbf{g}+\mathbf{f}_{j}=0 \\
\sum M_{O}=0 \\
\mathbf{c}_{f r j} \times \mathbf{f}_{f r j}+\mathbf{c}_{r r j} \times \mathbf{f}_{r r j}+\mathbf{a}_{j}^{b} \times \mathbf{f}_{j}+m_{I} \cdot \mathbf{e}_{j}^{b} \times \mathbf{g}+m_{I I} \cdot \mathbf{h}_{j}^{b} \times \mathbf{g}=0
\end{gathered}
$$

where $m_{I}$ and $m_{I I}$ are masses of the telescopic boom and mobile crane and their gravitational forces are acting at points $E_{j}$ and $H_{j}$, respectively, as shown in Fig. 3(a). $\mathbf{h}_{j}^{b}$ and $\mathbf{e}_{j}^{b}$ are the position vector of the center of gravity $H_{j}$ and telescopic boom point $E_{j} . \mathbf{c}_{f r j}$ and $\mathbf{c}_{r r j}$ are the position vector from the origin $O$ to the frontal and rear sides of the mobile crane as shown in Fig. 3(b). The mobile crane is said to be rolling if it turns over about the axis $u_{j}$. It happens since the right reaction forces $\left(\mathbf{f}_{r 1 j}\right.$ and $\left.\mathbf{f}_{r 2 j}\right)$ are very high and the left reaction forces $\left(\mathbf{f}_{r 3 j}\right.$ and $\left.\mathbf{f}_{r 4 j}\right)$ are null or vice versa. Accordingly, the right and left reaction forces are respectively defined as follows:

$$
\begin{aligned}
& \mathbf{f}_{r g j}=\mathbf{f}_{r 1 j}+\mathbf{f}_{r 2 j} \\
& \mathbf{f}_{l j j}=\mathbf{f}_{r 3 j}+\mathbf{f}_{r 4 j}
\end{aligned}
$$

The forces equilibrium and moment at point $O$ is written as: 


$$
\begin{gathered}
\sum \mathbf{f}=0 \\
\mathbf{f}_{r g j}+\mathbf{f}_{l j j}+m_{I} \cdot \mathbf{g}+m_{I I} \cdot \mathbf{g}+\mathbf{f}_{j}=0 \\
\sum M_{O}=0 \\
\mathbf{c}_{r g j} \times \mathbf{f}_{r g j}+\mathbf{c}_{l j j} \times \mathbf{f}_{l j}+\mathbf{a}_{j}^{b} \times \mathbf{f}_{j}+m_{I} \cdot \mathbf{e}_{j}^{b} \times \mathbf{g}+m_{I I} \mathbf{h}_{j}^{b} \times \mathbf{g}=0
\end{gathered}
$$

where $\mathbf{c}_{l j}$ is the vector position from the origin $O$ to the midpoint between points $C_{3 j}$ and $C_{4 j}$. The vector position $\mathbf{c}_{r g j}$ point from origin $O$ to the mid-point between points $C_{l j}$ and $C_{2 j}$ as shown in Fig. 3(b).

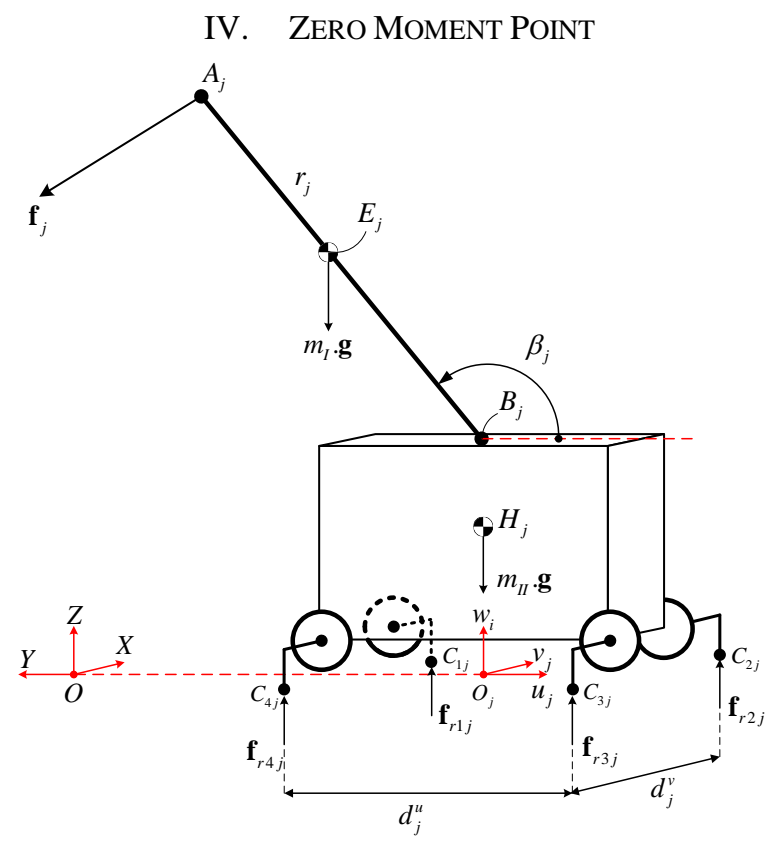

(a) Isometric view

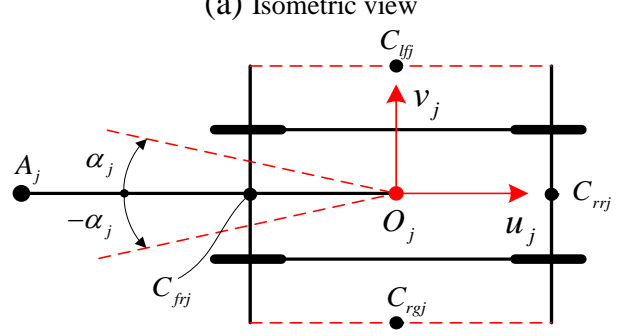

(b) Top View

Figure 3. Free-body diagram of a mobile crane

Zero Moment Point (ZMP) is a concept to evaluate the robot stability. When a mobile robot executing a given task, it has a ground contact point that is tangent to the ground surface [14]. In this paper, ZMP is defined as a point within the mobile cranes where the sum of moments due to frontal and rear reaction forces is null for tipping; and the sum of moments due to right and left reaction forces are null for rolling. ZMP is computed in the mobile coordinate $\left(u_{j}, v_{j}, w_{j}\right)$, hence the Cartesian coordinates of $A_{j}$ should be expressed into the mobile frame. As a result, the sum of moments at the point $O_{j}$ can be formulated for tipping analysis, as follows:

$$
M_{o j}+\left(\mathbf{f}_{f r j}+\mathbf{f}_{r r j}\right) \times \mathbf{d}_{j}=0
$$

where $\mathbf{d}_{j}$ is a vector that donates the ZMP of mobile frame. The mobile crane will not tip about the $v_{j}$, which means that ZMP will be within the points $C_{1 j}$ to $C_{2 j}$ or within the length $d_{j}^{u}$ as shown in Fig. 3(a). By solving Eq. (12), the length $d_{j}^{u}$ can be determined as:

$$
d_{j}^{u}=\frac{\left(a_{j}^{w} \cdot f_{j}^{u}\right)-\left(a_{j}^{u} \cdot f_{j}^{w}\right)-\left(m_{I} \cdot \mathrm{e}_{j}^{u} \cdot \mathrm{g}\right)}{f_{f r j}^{w}+f_{r r j}^{w}}
$$

The sum of the moment at point $O$ can be formulated for rolling analysis, as follow:

$$
M_{o j}+\left(\mathbf{f}_{l j j}+\mathbf{f}_{r g j}\right) \times \mathbf{d}_{j}=0
$$

The mobile crane will not roll about the axis $u_{j}$, which means that ZMP will be within the points $C_{1 j}$ and $C_{4 j}$ or within the length $d_{j}^{v}$ as shown in Fig. 3(a). By solving Eq. (14), the length $d_{j}^{v}$ can be determined as:

$$
d_{j}^{v}=\frac{\left(a_{j}^{v} \cdot f_{j}^{w}\right)+\left(a_{j}^{w} \cdot f_{j}^{v}\right)-\left(m_{I} \cdot \mathrm{e}_{j}^{v} \cdot \mathrm{g}\right)}{f_{l f i}^{w}+f_{r g i}^{w}}
$$

Accordingly, the mobile cranes will be statically stable if and only if the lengths $d_{j}^{u}$ and $d_{j}^{v}$ are the dimension of the mobile cranes.

\section{RECONFIGURATION PLANNING}

Reconfiguration is conducted by extending/retracting the length of the telescopic boom $\left(r_{j}\right)$ and orientating pitch and/or yaw angles $\left(\beta_{j}\right.$ and $\left.\alpha_{j}\right)$, as shown in Fig. 3. One non-reconfiguration case and three reconfiguration plans are proposed as follows:

- Plan 0: $r_{j}=1 m, \alpha_{j}=0, \beta_{j}=105^{\circ}$

- Plan 1: $\beta_{j}=105^{\circ}, r_{j}$ and $\alpha_{j}$ are reconfigured

- Plan 2: $\alpha_{j}=0, r_{j}$ and $\beta_{j}$ are reconfigured

- Plan 3: $r_{j}, \beta_{j}$ and $\alpha_{j}$ are reconfigured.

Three mobile cranes are located symmetrically with respect to origin $O$. They form an equilateral triangle such that $\gamma_{1}=330^{\circ} \gamma_{2}=90^{\circ}$ and $\gamma_{3}=210^{\circ}$ as shown in Fig. 1 . The distance of each mobile crane to origin $O$ is $\rho_{j}=3 \mathrm{~m}$.

The tracking of end-effector will be evaluated along the pick-and-place trajectory. The quadratic curve with two $\mathrm{x}$ intercepts has been selected to be the trajectory and the equation is written as follows:

$$
\begin{aligned}
& x=x_{A}-x_{B} \\
& y=0 \\
& z=3\left(-x^{2}+x_{B} x\right)
\end{aligned}
$$

For all plans, the end-effector starts from the initial point $x_{A}=0$ at point $A$ with time $t=0$ to the desired point $x_{B}=0.5 \mathrm{~m}$ at point $B$ with time $t=10 \mathrm{~s}$. 


\section{RESULTS AND DISCUSSIONS}

WFW is said to be a set of poses of end-effector that can maintain the static equilibrium of the mobile cranes and positive cable tension under external force. The workspace of Plan 0 is shown in Fig. 4. By increasing the payload, the cable tension will also increase then the mobile cranes will be unstable and the workspace is smaller as shown in Fig. 4(b). Base on the result of ZMP of Plan 0 in TABLE III, the mobile cranes cannot handle a payload of $5.5 \mathrm{~kg}$, hence, the second mobile crane will be roll-over as shown in this link ${ }^{1}$. Therefore, the concept of reconfiguration is introduced and will be analyzed hereafter

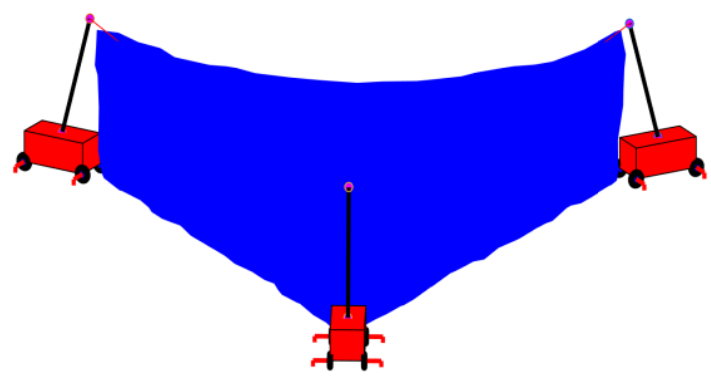

(a) WFW

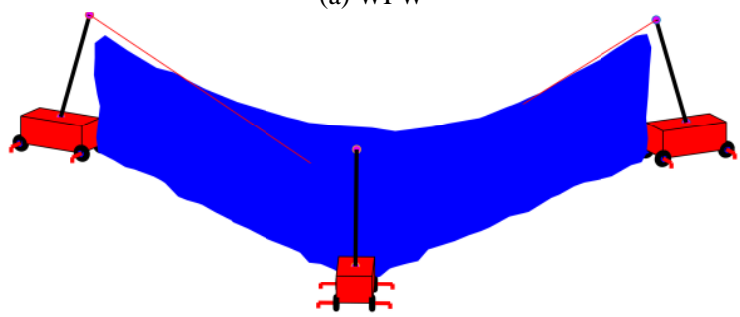

(b) Tipping/rolling-free workspace

Figure 4. Workspace of Plan 0

TABLE I. TENSION DistRIBUTION

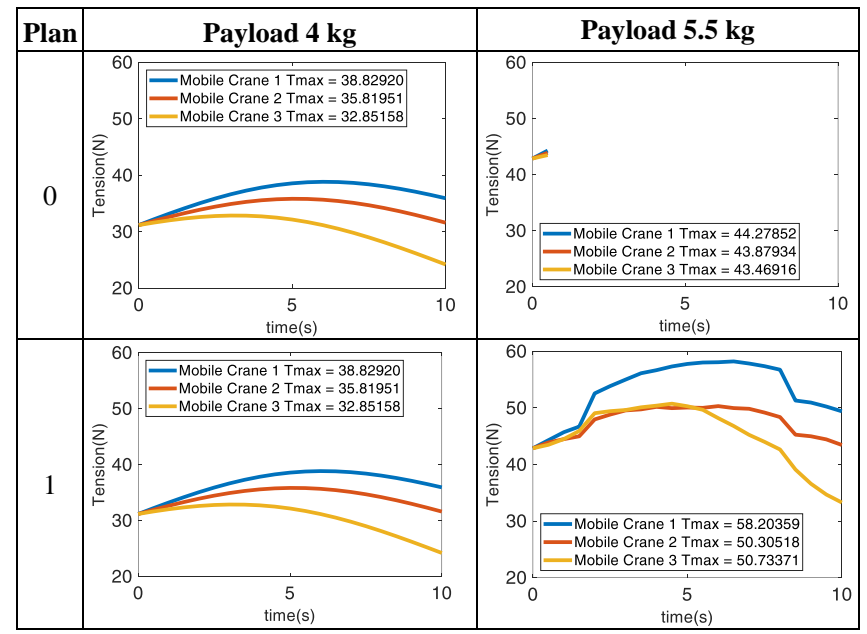

\footnotetext{
${ }^{1}$ Plan 0: https://itsacid-
}

my.sharepoint.com/:v:/g/personal/210000011_staff_integra_its_ac_id/EV WC4CGKbF9Eu_tyhfw98nABjJPF5oLb_9VyglmLJVHzxg?e=u14yDk

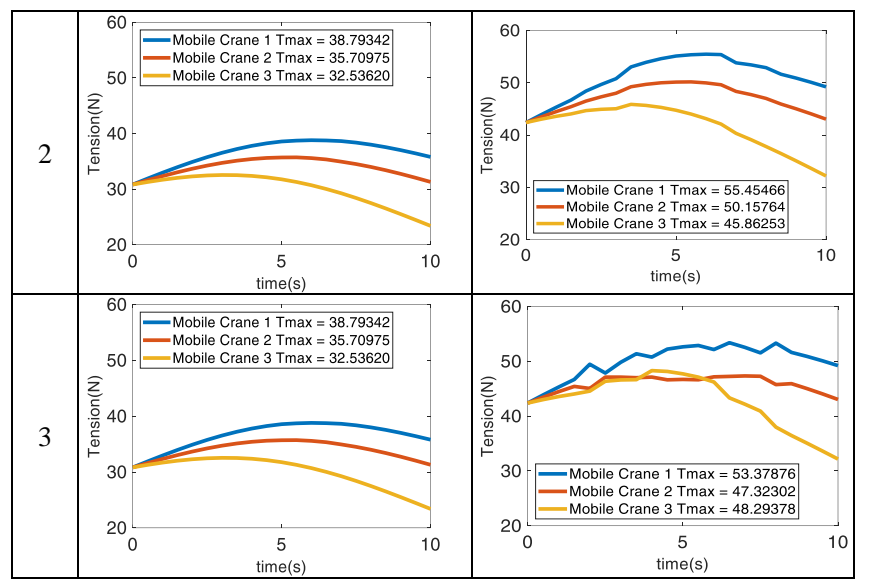

TABLE II. ZERO MOMENT POINT FOR TIPPING

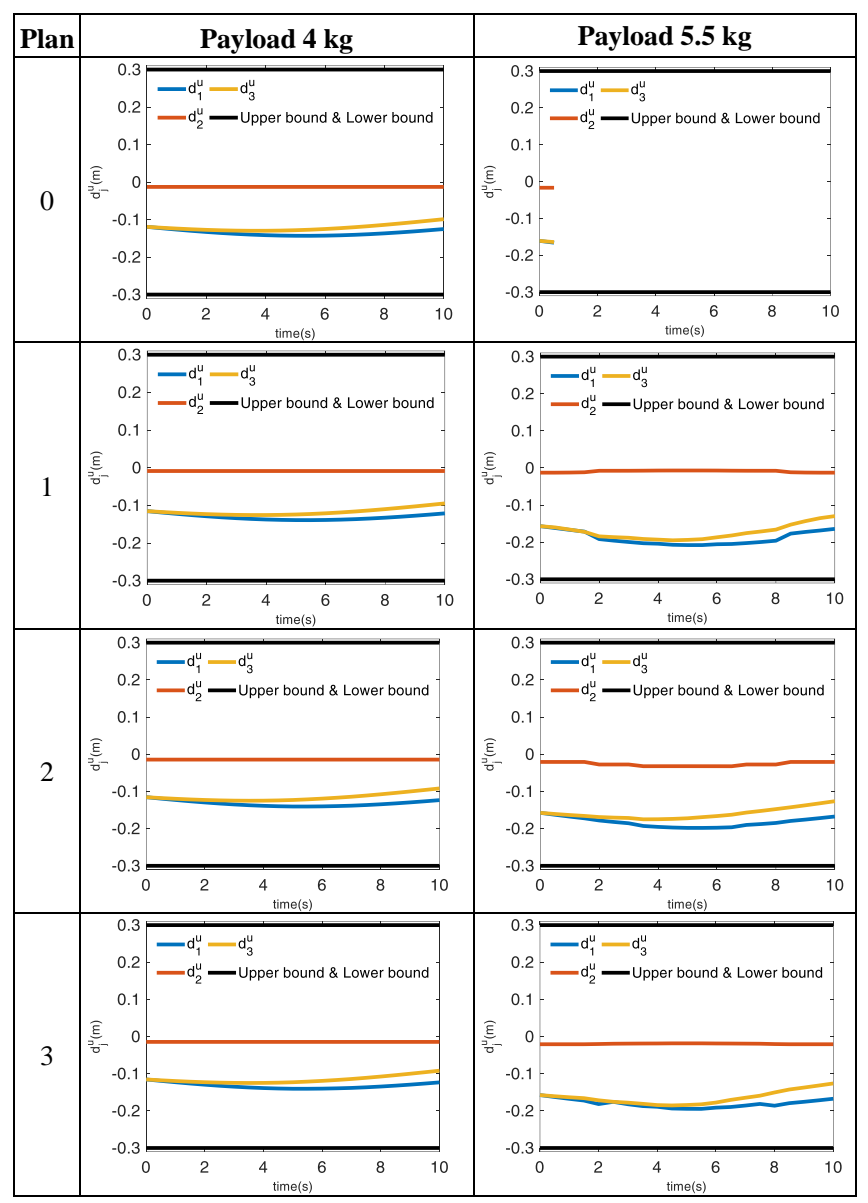

TABLE III. ZERO MOMENT POINT FOR ROLLING

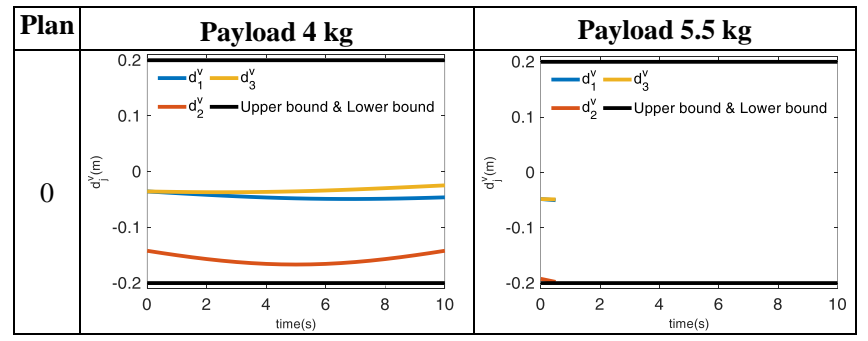




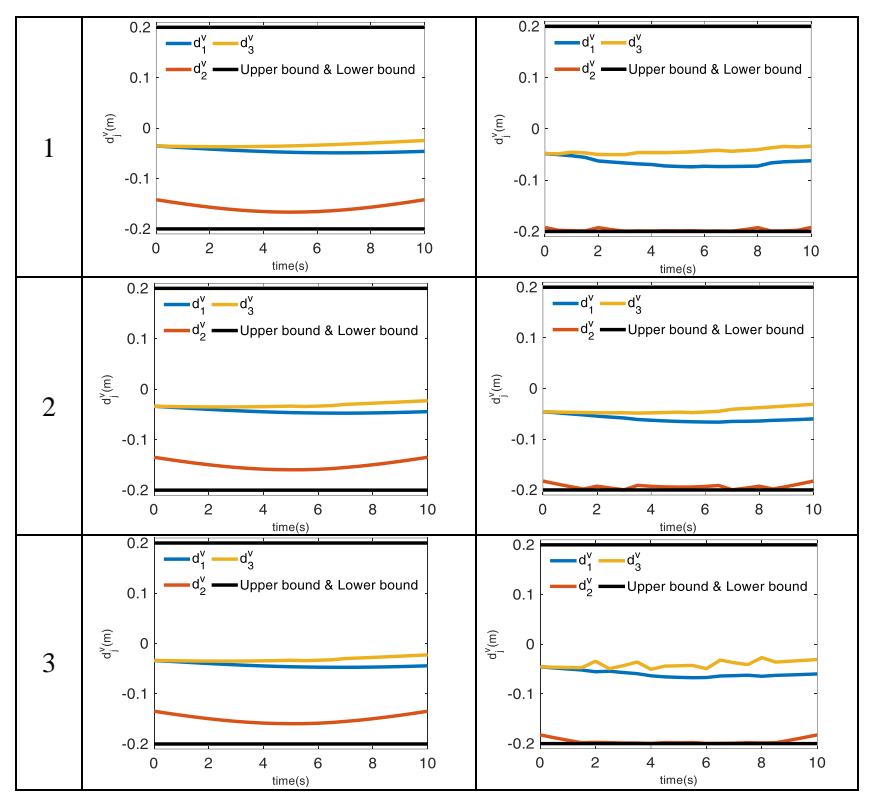

As shown in TABLE I, the cable tensions begin at the initial point with the same value as the desired point for payload $4 \mathrm{~kg}$. However, if the payload is increased to be $5.5 \mathrm{~kg}$, mobile cranes of Plan 0 will not be able to handle the great value of cable tensions and become unstable at $t \sim 1 \mathrm{~s}$. Reconfigurable of the telescopic boom, the end-effector can follow the trajectory without turning over of the mobile cranes. Plan 3 is the best plan, the maximum cable tension of the first and second mobile crane is lower compared to Plan 1 and Plan 2. However, the third mobile crane is highest because $r_{j}, \beta_{j}$ and $\alpha_{j}$ is changed together when giving a task. The animation of the reconfigurable telescopic boom can be seen in these links: Plan $1^{2}$ Plan $2{ }^{3}$ and Plan $3{ }^{4}$.

ZMP analysis is illustrated in TABLE II for tipping and TABLE III for rolling. For Plan 0, We can recognize that the second mobile cranes will be rolling because $d_{2}^{v}$ payload $5.5 \mathrm{~kg}$ rapidly increases to the lower bound. The second mobile crane is not turned over because the value of $d_{2}^{v}$ reconfiguration telescopic boom is in the limitation of ZMP.

\section{CONCLUSIONS}

This paper proposed a mathematical model of CDPR with multiple mobile cranes. The reconfigurable telescopic boom is attached at the top of mobile cranes. The location of the mobile crane is fixed, while the telescopic boom can be reconfigured. The end-effector and mobile crane are maintained in a static equilibrium; hence WFW can be

\footnotetext{
2 Plan 1: https://itsacid-

my.sharepoint.com/:v:/g/personal/210000011_staff_integra_its_ac_id/Ee_d ZZi4RREkF_0A53i8RQBeY1CmKnSh1o2XSHNP3jO7A?e=DWBB10

${ }^{3}$ Plan 2: https://itsacid-

my.sharepoint.com/:v:/g/personal/210000011_staff_integra_its_ac_id/Eat0 V2pJYZtFmTbmwLsHJ18BDn4oS0yeo2MmjmIQzpn81Q?e=sKHfuB

${ }^{4}$ Plan 3: https://itsacid-

my.sharepoint.com/:v:/g/personal/210000011_staff_integra_its_ac_id/EU4 4Jf3wvgpNqLyImzG_w1MBsLomKHZgaOTaRNOBp6P18w?e=xZVZTQ
}

determined. The results showed that cable tension values along Plan 1 and Plan 2 are higher than those obtained along Plan 3. The cable tension is also having a significant effect on the stability of the mobile cranes. ZMP defined the stability of the mobile crane and we can recognize that the mobile cranes will be tipping/rolling-over if the payload is increased.

\section{ACKNOWLEDGMENT}

This work is supported by the Ministry of Research and Higher Education of Indonesia, under the scheme of International Collaboration Research 2018-2020.

\section{REFERENCES}

[1] S. Qian, B. Zi, W. W. Shang, and Q. S. Xu, "A review on cabledriven parallel robots," Chinese J. Mech. Eng. (English Ed., vol. 31, no. 4, p. 66, 2018.

[2] A. Pott, H. Mütherich, W. Kraus, V. Schmidt, P. Miermeister, and A. Verl, "IPAnema: a family of cable-driven parallel robots for industrial applications," in Cable-Driven Parallel Robots, Springer, 2013, pp. 119-134.

[3] J. Hanafie, L. Nurahmi, S. Caro, and B. Pramujati, "Design optimization of spatial four cables suspended cable driven parallel robot for rapid life-scan," in AIP Conference Proceedings, 2018, vol. 1983, no. 1

[4] V. A. Handojo, A. T. Syamlan, L. Nurahmi, B. Pramujati, M. N. Tamara, and U. Wasiwitono, "Cable Driven Parallel Robot with Big Interference-Free Workspace," in Mechanism and Machine Science, Springer, pp. 43-56.

[5] A. T. Syamlan, L. Nurahmi, M. N. Tamara, and B. Pramujati, "Dynamic trajectory planning of reconfigurable suspended cable robot," Int. J. Dyn. Control, vol. 8, no. 3, pp. 887-897, 2020

[6] N. Pedemonte et al., "Fastkit: A mobile cable-driven parallel robot for logistics," in Advances in Robotics Research: From Lab to Market, Springer, 2020, pp. 141-163.

[7] C. Alias, I. Nikolaev, E. G. C. Magallanes, and B. Noche, "An Overview of Warehousing Applications based on Cable Robot Technology in Logistics," in 2018 IEEE International Conference on Service Operations and Logistics, and Informatics (SOLI), 2018, pp. 232-239.

[8] T. Rasheed, P. Long, D. Marquez-Gamez, and S. Caro, "Tension distribution algorithm for planar mobile cable-driven parallel robots," in Cable-Driven Parallel Robots, Springer, 2018, pp. 268-279.

[9] T. H. Lim, Y. S. Kim, J. Hwan, H. S. Lee, and S. Y. Yang, "Development of tipping-over rate computation system for hydraulic excavator having crane function," in Proceedings. The 8th RussianKorean International Symposium on Science and Technology, 2004. KORUS 2004., 2004, vol. 3, pp. 76-79 vol. 3.

[10] F. Okoli, Y. Lang, O. Kermorgant, and S. Caro, "Cable-Driven Parallel Robot Simulation Using Gazebo and ROS," in ROMANSY 22-Robot Design, Dynamics and Control, Springer, 2019, pp. 288295 .

[11] T. Rasheed, P. Long, D. Marquez-Gamez, and S. Caro, "Available wrench set for planar mobile cable-driven parallel robots," in 2018 IEEE International Conference on Robotics and Automation (ICRA), 2018, pp. 962-967.

[12] T. Rasheed, P. Long, and S. Caro, "Wrench-Feasible Workspace of Mobile Cable-Driven Parallel Robots," J. Mech. Robot., vol. 12, no. 3 , 2020.

[13] C. Gosselin, "Global planning of dynamically feasible trajectories for three-DOF spatial cable-suspended parallel robots," Cable-Driven Parallel Robot., 2013.

[14] P. Sardain and G. Bessonnet, "Forces acting on a biped robot. Center of pressure-zero moment point," IEEE Trans. Syst. Man, Cybern. A Syst. Humans, vol. 34, no. 5, pp. 630-637, 2004. 